\title{
Hormonal induction of gamete release, and in- vitro fertilisation, in the critically endangered Southern Corroboree Frog, Pseudophryne corroboree
}

\author{
Phillip G Byrne ${ }^{1 * \dagger}$, Aimee J Silla ${ }^{2 \dagger}$
}

\begin{abstract}
Background: Conservation Breeding Programs (CBP's) are playing an important role in the protection of critically endangered anuran amphibians, but for many species recruitment is not successful enough to maintain captive populations, or provide individuals for release. In response, there has been an increasing focus on the use of Assisted Reproductive Technologies (ART), including the administration of reproductive hormones to induce gamete release followed by in vitro fertilisation. The objective of this study was to test the efficacy of two exogenous hormones to induce gamete release, for the purpose of conducting in vitro fertilisation (IVF), in one of Australia's most critically endangered frog species, Pseudophryne corroboree.

Methods: Male frogs were administered a single dose of either human chorionic gonadotropin (hCG) or luteinizing hormone-releasing hormone ( $(\mathrm{HRHa})$, while female frogs received both a priming and ovulatory dose of LHRHa. Spermiation responses were evaluated at 3, 7, 12, 24, 36, 48, 60 and $72 \mathrm{~h}$ post hormone administration $(\mathrm{PA})$, and sperm number and viability were quantified using fluorescent microscopy. Ovulation responses were evaluated by stripping females every $12 \mathrm{~h}$ PA for 5 days. Once gametes were obtained, IVF was attempted by combining spermic urine with oocytes in a dilute solution of simplified amphibian ringer (SAR).

Results: Administration of both hCG and LHRHa induced approximately $80 \%$ of males to release sperm over $72 \mathrm{~h}$. Peak sperm release occurred at $12 \mathrm{~h}$ PA for hCG treated males and $36 \mathrm{~h}$ PA for LHRHa treated males. On average, LHRHa treated males released a significantly higher total number of live sperm, and a higher concentration of sperm, over a longer period. In female frogs, administration of $\mathrm{LHRHa}$ induced approximately $30 \%$ of individuals to release eggs. On average, eggs were released between 24 and $48 \mathrm{~h}$ PA, with a peak in egg release at $36 \mathrm{~h}$ PA. IVF resulted in a moderate percentage (54.72\%) of eggs being fertilised, however all resultant embryos failed prior to gastrulation.

Conclusions: Hormone treatment successfully induced spermiation and ovulation in P. corroboree, but refinement of gamete induction and IVF techniques will be required before ART protocols can be used to routinely propagate this species.
\end{abstract}

\section{Background}

Environmental change driven by anthropogenic activities is causing unprecedented rates of species extinction, presenting a major threat to global biodiversity [1]. Among vertebrates, all classes have suffered high

\footnotetext{
* Correspondence: phillip.byrne@sci.monash.edu.au

+ Contributed equally

'School of Biological Sciences, Monash University, Melbourne Vic, Australia

Full list of author information is available at the end of the article
}

extinction rates, but amphibians have been most severely impacted. Based on recent estimates, more than one-third of the worlds amphibians are threatened with extinction [2,3], and almost one-half of the remaining species are in a state of decline [2]. In response to this crisis, the international Amphibian Conservation Action Plan (ACAP), devised in 2005, urged the establishment of captive assurance colonies for threatened species $[4,5]$. In accordance with this recommendation, a large

\section{Biomed Central}


number of institutions worldwide have initiated captive breeding programmes for declining and endangered amphibians. However, in almost all cases, breeding attempts have failed due to the inherent difficulties associated with simulating the complex combination of social and environmental factors that trigger amphibians to breed [6,5]. In reaction to this captive breeding crisis, there has been a growing interest in determining whether threatened amphibians can be propagated, and genetically managed, using assisted reproductive technologies (ART) $[5,7,8]$.

One component of ART is the artificial manipulation of reproductive events using exogenous hormones. Specifically, males and females are administered hormones to stimulate the production and release of gametes (spermatozoa and oocytes), which are then used to generate embryos via in vitro fertilisation (IVF), also referred to as artificial fertilisation (AF) [5]. Among anurans (frogs and toads), it has been known for several decades that exogenous gonadotropins, and gonadotropin-releasing hormones, can be used to induce both sperm release (spermiation) and oocyte release (ovulation) [9-12]. Pituitary extracts are an effective source of amphibian gonadotropins and such preparations have been successfully used to induce gamete release in various anuran species, including Bufo arenarum, Rana pipiens, Hyla regilla and Eleutherodactylus coqui [9,10,13-16]. However, the use of pituitary extracts is now strongly discouraged due to a high risk of pathogen transmission [5,7], and because production of pituitary preparations requires the euthanasia of large numbers of reproductively mature anurans [17]. An alternative approach is the use of synthetic hormones, in particular, commercially available analogues of luteinizing-hormone releasing hormone (LHRH) and human chorionic gonadotropin (hCG) [8,17-19].

Luteinizing-hormone releasing hormone is a hypothalamic hormone that acts by stimulating the anterior pituitary to synthesize and release natural luteinizing hormone (LH), which in turn stimulates gonadal activity. In contrast, hCG acts by mimicking $\mathrm{LH}$, due to identical alpha and shared beta subunits [20], bypassing the hypothalamic-pituitary-gonadal axis to exert a direct influence on the gonads [21]. Evidence that synthetic analogues of LHRH and hCG can successfully induce gamete release has been obtained for a broad diversity of anuran species $[7,17,18,22-26]$, but the efficacy of these hormones has been found to vary considerably. For example, LHRHa is significantly more effective than hCG at stimulating ovulation in Eleutherodactylus coqui [17], but hCG is highly effective at stimulating ovulation in Xenopus laevis [26].

Although there is still much to learn about the relative efficacy of hCG and LHRHa across species, baseline knowledge concerning their potency has permitted IVF to be attempted in a small, but growing number of anuran families, including the bufonidae [8], pipidae [26] and myobatrachidae [27]. Surprisingly, however, almost all anuran IVF studies conducted to date have refrained from artificially fertilizing oocytes using hormonally induced sperm, instead opting to use sperm obtained from testes macerates [13,27-29]. The benefit of conducting IVF using testes macerates is that sperm can be obtained in high concentrations, and can also be acquired at the exact moment when females begin ovulating, eliminating the need for sperm storage [19]. Given these practical advantages, euthanizing males for the purpose of IVF might be useful in common species, but this approach cannot be justified in endangered species where individual animals are of high genetic value $[5,7]$.

To date, few studies have attempted IVF in anurans using hormonally induced gametes collected from live animals, and outcomes have been highly variable. For example, Waggener and Carrol [22] achieved 100\% fertilisation success in the leptodactylid frogs Lepidobatrachus laevis and L. illanensis [22], but Browne et al. [8] reported a mean fertilisation success of $12.7 \%$ in the endangered toad Bufo baxteri. This extreme variance in IVF success, which is probably related to species-specific differences in reproductive mode and physiology, suggests that protocols for combining hormonally induced gametes are not readily transferable between species [19]. Given this inherent level of unpredictability, there is a need to develop techniques for collecting and combining gametes obtained from live individuals. In particular, there is an urgent need to develop these protocols for endangered species $[7,8]$.

The southern corroboree frog Pseudophryne corroboree, is one of Australia's most critically endangered frog species [30]. Of the species known to be extant in Australia, P. corroboree was ranked by the Australasian Regional Association of Zoological Parks and Aquaria as the highest priority anuran requiring ex-situ conservation [31]. The distribution of P. corroboree is highly restricted, with the species confined to a linear distance of $51 \mathrm{~km}$ within subalpine regions of Koscuiszko National Park [32]. According to recent field surveys, there are currently less than 50 individuals remaining at natural breeding sites, and the species is predicted to go extinct in the wild within the next ten years [33]. Population declines in $P$. corroboree were first observed in the 1980's, and since 1996 the species has been the focus of an intensive management and recovery programme [33,34]. Early management of the species concentrated on habitat protection, but more recently efforts have turned towards the establishment of captive assurance populations $[33,35]$. At present, multiple 
populations of $P$. corroboree are being maintained in zoos and biological institutions throughout Australia, but successful breeding and recruitment in captivity has been limited. Despite this critical situation, there has been no attempt to bolster captive breeding activity using assisted reproductive technologies.

The aim of this study was twofold. First to test the efficacy of using LHRH and hCG to induce spermiation, and LHRH to induce ovulation, in captively reared $P$. corroboree, and second, to test whether hormonally induced sperm and oocytes can be used to generate embryo's via in-vitro fertilisation (IVF).

\section{Methods}

All research was conducted in compliance with the Monash University Animal Ethics Committee (AEC), permit number BSCI/2009/27.

\section{Study population}

Frogs were obtained from a captive colony maintained at the Amphibian Research Centre (ARC) in Melbourne Victoria. The captive colony was established by collecting natural egg clutches from multiple populations throughout the species range during the 2004 and 2005 breeding seasons. The eggs were reared to maturity and housed in indoor terrariums $(150 \times 43 \times 38 \mathrm{~cm})$ exposed to seasonal fluctuations in temperature and photoperiod that mimicked natural conditions. Frogs used in this study were approximately 4-5 years old because sexual maturity in $P$. corroboree is not reached until 3-4 years post-metamorphosis [36]. In total, the study involved 24 males and 25 females, but one male was not treated. In P. corroboree phenotypic traits do not provide reliable indicators of sex. Therefore, prior to commencement of the study all frogs were genetically sexed using Amplified Fragment Length Polymorphism (AFLP) analysis, with the presence of a 66 bp DNA marker (representing a Y chromosome sequence) diagnostic for males $[37,38]$.

Frogs were collected from the ARC and transported to Monash University (Clayton campus) where they were held for the duration of the study (January 29-April 9, 2009). On the day of collection, frogs were weighed and snout-vent length measured before being randomly assigned to same sex groups $(n=6$ frogs per group, with the exception of one female group that contained 7 frogs). Groups of individuals were housed in plastic enclosures $(360 \mathrm{~mm} \times 200 \mathrm{~mm} \times 170 \mathrm{~mm})$, each containing a layer of fine gravel $(\sim 15 \mathrm{~cm}$ thick) covered with a layer of sphagnum moss ( $\sim \mathrm{cm}$ thick). Once a week, containers were flushed with approximately $2 \mathrm{~L}$ of deioinized water and frogs were fed ten-day old crickets $(\sim 200$ per container). All containers were kept in a constant temperature room maintained on a $17^{\circ} \mathrm{C} / 12^{\circ} \mathrm{C}$ day/night temperature cycle and a $14.5 \mathrm{~h} / 9.5 \mathrm{~h}$ light/dark cycle.

\section{Hormonal induction of spermiation}

Males were administered a single dose of either 20 IU per gram bodyweight hCG (chorolon ${ }^{\circ}$ ) ( $\mathrm{n}=6$ males) or $5 \mu \mathrm{g}$ per gram bodyweight LHRHa (Leuprorelin oxo-ProHis-Trp-Ser-Tyr-[d-leu]-Leu-Arg-Pro-NHEt: Lucrin $\left.{ }^{\oplus}\right)$ ( $\mathrm{n}=$ 11 males). These doses were selected because they approximate doses previously found to induce gamete release in anurans $[5,22,24,39]$. Hormones were diluted in $100 \mu \mathrm{L}$ of Simplified Amphibian Ringer $(113 \mathrm{mM}$ $\left.\mathrm{NaCl}, 2 \mathrm{mM} \mathrm{KCl}, 1.35 \mathrm{mM} \mathrm{CaCl}_{2}, 1.2 \mathrm{mM} \mathrm{NaHCO}{ }_{3}\right)$ and administered via subcutaneous injection into the dorsal lymph sac. As a control for the injection and handling procedures, a third group of frogs $(n=6)$ were administered $100 \mu \mathrm{L}$ of Simplified Amphibian Ringer (SAR). Following hormone administration, frogs were returned to plastic holding tanks $(50 \mathrm{~mm} \times 90 \mathrm{~mm}$ ) containing moist sponge hydrated with $5 \mathrm{~mL}$ of distilled water. Under these conditions, frogs were sufficiently hydrated to permit urine collection at each of the sampling times.

Spermic urine was collected at $3,7,12,24,36,48$, $60 \& 72 \mathrm{~h}$ post hormone administration (PA). The collection method involved gently inserting the end of a glass microcapillary tube (fire polished and cooled) into the cloaca to stimulate urination. Immediately post collection, the volume of urine collected was measured in microlitres $(\mu \mathrm{L})$, and the sample was then homogenized with $5 \mu \mathrm{L}$ of a 1:50 dilution of SYBR-14 (Invitrogen L7011), and then incubated in the dark for $7 \mathrm{~min}$. Following this, a $2 \mu \mathrm{L}$ aliquot of propidium iodide (PI) was then added and the solution was incubated in the dark for a further $7 \mathrm{~min}$. SYBR-14 and PI are membrane permanent DNA stains that are commonly used to quantify sperm number and viability in anurans $[39,40]$ and other vertebrates [38]. SYBR-14 specifically stains the DNA of live (viable) sperm, while PI specifically stains the DNA of dead (non-viable) sperm. Under UV light, live sperm (stained with SYBR-14) fluoresce bright green, while dead sperm (stained with PI) fluoresce bright red [41]. Immediately after staining, wet mount slides were prepared and the viability of sperm was evaluated within $30 \mathrm{~min}$ using fluorescent microscopy at a wavelength of $490 \mathrm{~nm}$. For each sample, we calculated the total sperm count, sperm concentration (number of sperm/urine volume $(\mu \mathrm{L}) \times 1000)$, and sperm viability (the proportion of live/total sperm).

\section{Hormonal induction of ovulation}

Females were randomly allocated to one of two treatment groups; a hormone treatment ( $\mathrm{n}=17$ females) administered LHRHa (Lucrin $\left.{ }^{\oplus}\right)$, or a control treatment ( $\mathrm{n}=8$ females) administered Simplified Amphibian Ringer (SAR). For the hormone treatment, a stock solution of Lucrin ${ }^{\ominus}$ was diluted in Simplified Amphibian 
Ringer to produce a final concentration of $100 \mu \mathrm{g} \mathrm{mL}$. Females received an anovulatory dose of $1 \mu \mathrm{g}$ LHRHa per gram bodyweight diluted in $100 \mu \mathrm{L}$ of SAR administered via subcutaneous injection into the dorsal lymph sac. This dosage was administered to prime the ovary without inducing ovulation $[8,42]$. Twenty-six hours after administration of the 'priming dose', each female received an ovulatory dose of $5 \mu \mathrm{g}$ LHRHa per gram bodyweight. For the control treatment, females were administered $100 \mu \mathrm{L}$ of SAR in place of the priming and ovulatory doses. Following treatment, individual females were placed into plastic enclosures $(200 \mathrm{~mm} \times 120 \mathrm{~mm}$ $\times 90 \mathrm{~mm}$ ) lined with moist sponge and sphagnum moss. Individual animals were removed from their holding tanks $12 \mathrm{~h}$ PA of the ovulatory dose and stripping (expulsion of eggs from the oviducts) was attempted. Stripping was facilitated by holding a frog with its legs extended and gently applying pressure to the abdomen in a craniocaudal direction [21,43]. Stripping was attempted every $12 \mathrm{~h} \pm 0.5 \mathrm{~h}$ for a period of five days.

\section{In-vitro fertilisation (IVF)}

At each sampling time, any eggs expelled from a female were placed in an individual dry Petri dish and IVF was conducted using available spermic urine samples. An aliquot of approximately $170 \mu \mathrm{L}$ of pooled spermic urine was activated in approximately $100 \mu \mathrm{L}$ 1:4 SAR. Sperm concentrations used for IVF ranged between $1.14 \times 10^{2}$ and $2.87 \times 10^{2}$. The sperm solution was pipetted directly onto the oocytes and the dish was agitated for one minute. Each dish was enclosed within a petri dish and left to develop in a constant temperature room set to $10^{\circ} \mathrm{C}$. Developing embryos were supplied with $100 \mu \mathrm{L}$ of deionised water at $12 \mathrm{~h}$, and a further $1000 \mu \mathrm{L}$ at $24 \mathrm{~h}$ post fertilisation. Fertilisation success was calculated as the proportion of eggs at Gosner stage 4 to 6 [44] approximately $12 \mathrm{~h}$ post application of spermic urine to the oocytes. Embryonic development was checked every 6$12 \mathrm{~h}$ for a period of 7 days, and developmental stage quantified, using a stereo dissecting microscope.

\section{Statistical analyses}

The number of males that released sperm was compared between experimental treatments (LHRHa versus hCG), and between each experimental treatment and the control (hCG versus control, LHRHa versus control), using Fisher's exact tests. All comparisons were one-tailed due to the expectation of a positive treatment response. Comparison of mean total sperm count and mean total sperm concentration over the $72 \mathrm{~h}$ sampling period was made between treatments using Welch ANOVA's, due to unequal variance. Calculations of total sperm concentration only included sampling times in which sperm were released. Comparisons of sperm count and sperm concentration over time were made between treatments using repeated measures MANOVA's, with the main factors set as hormone treatment, and the within subject factors set as time. The MANOVA's were based on 6 equally spaced time intervals: 12 h, 24 h, 36 h, 48 h, 60 h and $72 \mathrm{~h} \mathrm{PA}$. Because the data violated the assumption of sphericity (Mauchly's test: $\mathrm{P}<0.05$ ), univariate analyses were corrected, and degrees of freedom adjusted, using the Greenhouse-Geisser method. The mean proportion of live sperm released over $72 \mathrm{~h}$ was compared between treatments using a student t-test. For all spermiation analyses, sperm counts were square root transformed, and sperm proportions were arcsine transformed. The number of females ovulating in response to hormone treatment (LHRHa injection) was compared to the control treatment (saline injection) using a one-tail Fisher's exact test. All statistical comparisons were performed using JMP software, with significance levels set at $P<0.05$.

\section{Results}

\section{Hormonal induction of spermiation}

No frogs $(0 / 6)$ released sperm following injection of a saline control, but a high proportion of males released sperm following injection of hCG $(83.3 \%, 5 / 6)$ and LHRHa $(81.8 \%, 9 / 11)$. The number of males releasing sperm was significantly higher in response to hormone treatment compared to the control treatment (control versus hCG, Fisher's exact test: $\mathrm{p}=0.007$; control versus LHRHa, Fisher's exact test $\mathrm{p}=0.002$ ), but the number of responding males did not significantly differ between hormone treatments (hCG versus LHRHa, Fisher's exact test: $\mathrm{p}=0.72$ ). Males treated with $\mathrm{hCG}$ started releasing sperm within 3 hrs post administration (PA), and ceased sperm release after $48 \mathrm{~h}$ PA (Figure 1). In contrast, males treated with LHRHa, did not commence sperm release until $7 \mathrm{~h} \mathrm{PA}$, and at $72 \mathrm{~h}$ PA over 25\% (3/11) of males were still releasing sperm (Figure 1). The highest proportion of males releasing sperm occurred between 12 and $48 \mathrm{~h}$ in response to hCG, and between 36 and $60 \mathrm{~h}$ in response to LHRHa (Figure 1).

The mean total number of sperm released over $72 \mathrm{~h}$ was more than 11 times higher in LHRHa treated males than in hCG treated males (Figure 2), and this difference was significant (Welch's ANOVA; $\mathrm{F}_{1,11.06}=11.28, \mathrm{P}=$ $0.006)$. There was no overall time effect on the number of sperm released (MANOVA: $\mathrm{F}_{3.01,36.15}=1.42, \mathrm{p}=$ $0.46)$ and no significant interaction between time and treatment (MANOVA: F $3.01,36.15=1.05, \mathrm{p}=0.38$ ), indicating that the number of sperm released did not differ between treatment groups over time. However, there was a significant treatment effect (MANOVA: $\mathrm{F}_{1,12}=$ $8.14, \mathrm{p}=0.01$ ), indicating that at each sampling period, LHRHa treated males generally released more sperm than hCG treated males (Table 1). Peak sperm release 


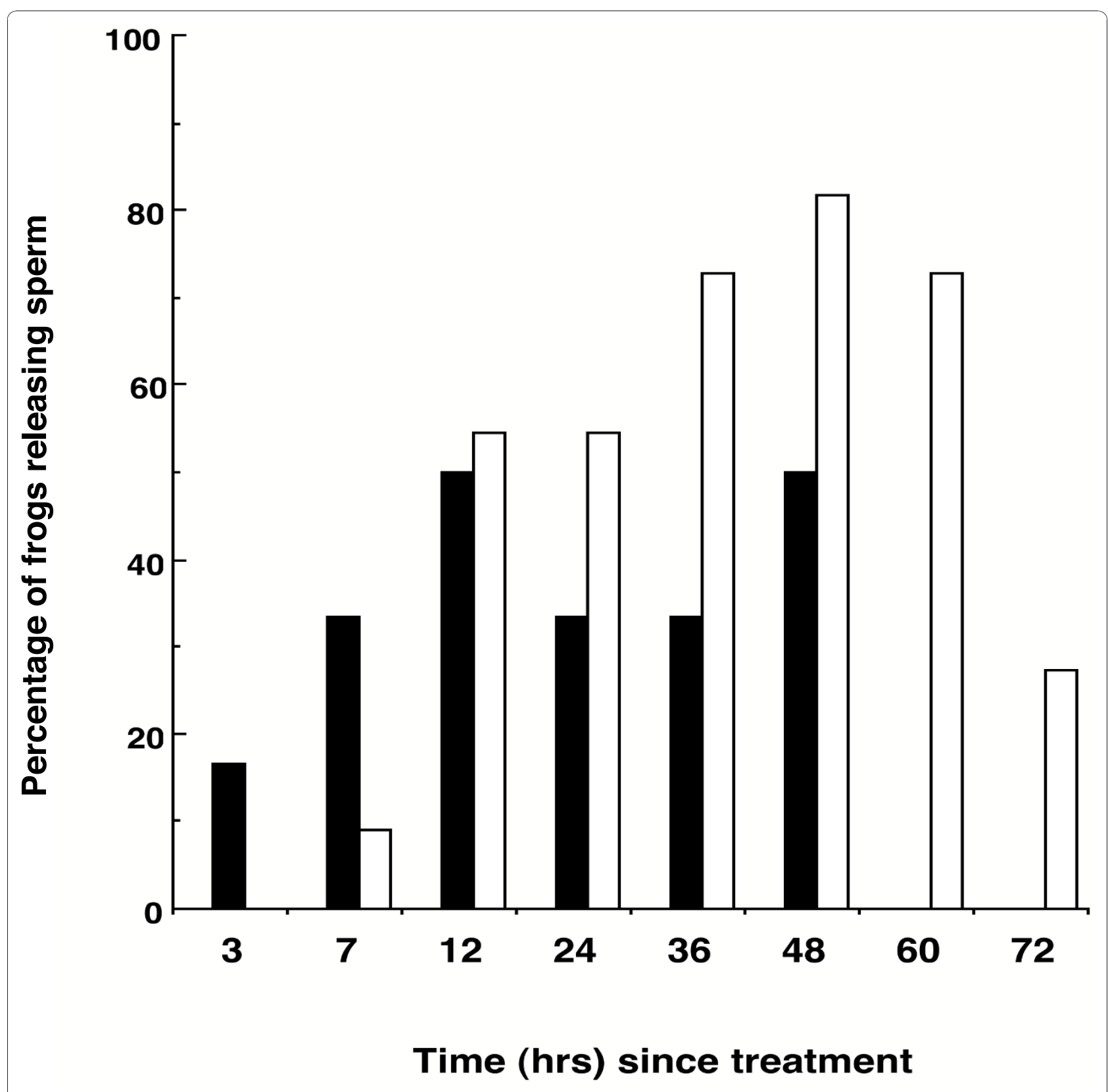

Figure 1 Percentage of hormone treated males releasing sperm over a $\mathbf{7 2} \mathbf{h}$ sampling period. Frogs were administered either hCG $(n=6$ males)(black bars) or LHRHa ( $n=11$ males)(white bars).

occurred at $12 \mathrm{~h}$ PA for hCG treated males, but not until $36 \mathrm{~h}$ PA for LHRHa treated males (Table 1).

Mean total sperm concentration was significantly higher in LHRHa treated males than in hCG treated males (Welch's ANOVA; $F_{1,11.70}=9.33, p=0.01$, Figure 3). Sperm concentration did not significantly differ over time (MANOVA: $\mathrm{F}_{2.19}, 26.32=2.68, \mathrm{p}=0.082$ ), and there was no significant interaction between time and treatment (MANOVA: $\mathrm{F}_{2.19,26.32}=1.79, \mathrm{p}=0.18$ ), indicating that over time sperm concentration did not differ between treatment. However, there was a significant overall treatment effect (MANOVA: F $1,12=18.31, \mathrm{p}=$ 0.001 ), indicating that at individual sampling times sperm concentration was generally higher for LHRHa treated males than hCG treated males (Table 1). Peak sperm concentration occurred at $12 \mathrm{~h}$ for hCG treated males and $36 \mathrm{~h}$ for LHRHa treated males, corresponding with peaks in total sperm number (Table 1).

The mean total proportion of live sperm (sperm viability) released over $72 \mathrm{~h}$, was almost $10 \%$ higher in 


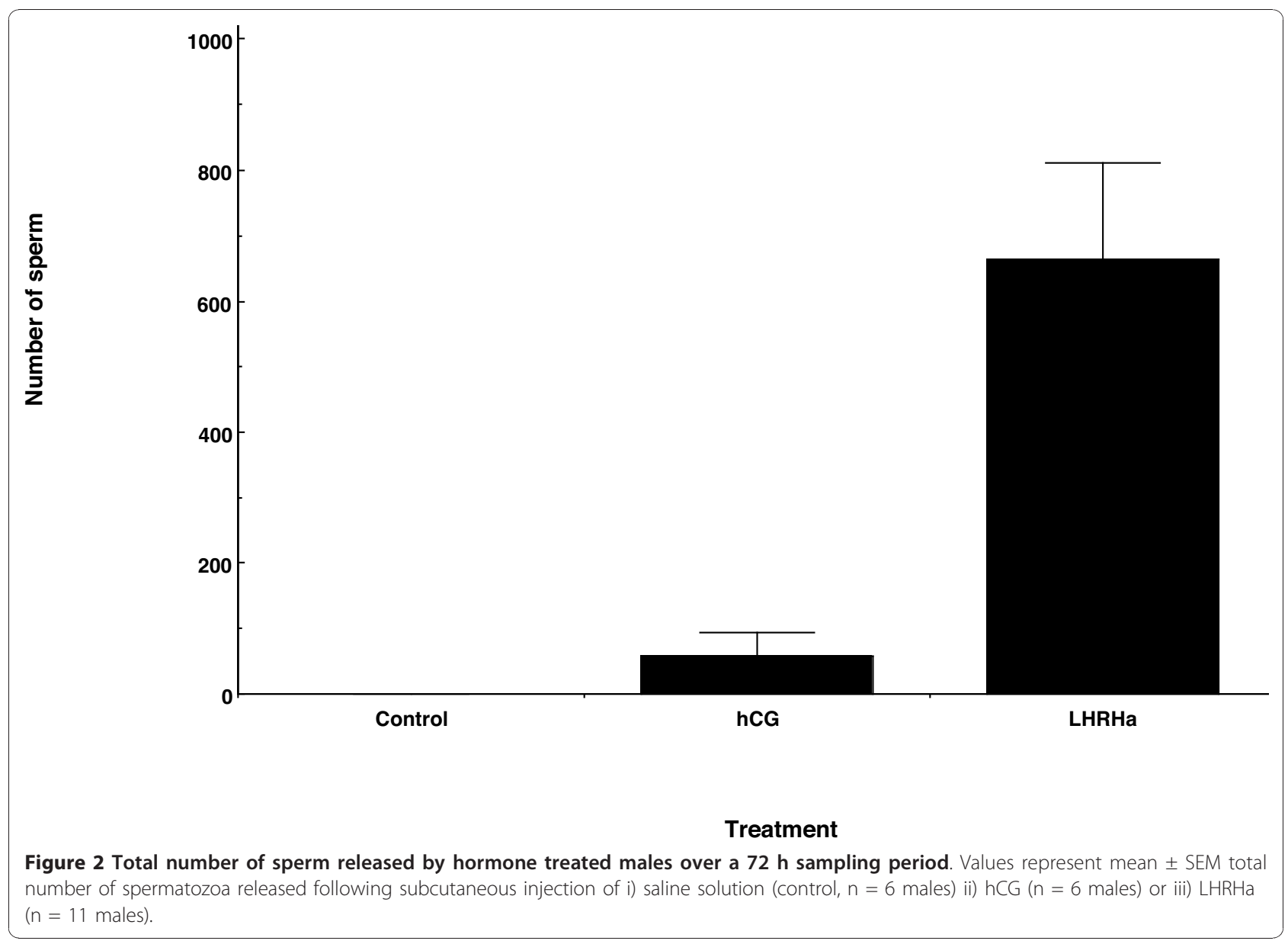

LHRHa treated males than in hCG treated males (Figure 4 ), and this difference was significant ( $\mathrm{t}$-test; $\mathrm{t}=2.31$, $\mathrm{df}=11, \mathrm{p}=0.04)$. Males treated with hCG released live sperm between 3 and $36 \mathrm{~h} \mathrm{PA}$, and over this period sperm viability was generally high $(>60 \%)$, but at $12 \mathrm{~h}$ $\mathrm{PA}$, which was the peak time for sperm release (maximum sperm number and concentration), average viability was lower than 35\% (Table 1). For LHRHa treated males, live sperm were released between 7 and $72 \mathrm{~h}$ PA, and the sperm viability remained above $60 \%$ up until 48 $\mathrm{h}$ PA, after which time viability started to drop (Table $1)$. At the time of peak sperm production and concentration (36 h PA), the proportion of live sperm was higher than $80 \%$ (Table 1$)$.

\section{Hormonal induction of ovulation}

No frogs $(0 / 8)$ released eggs following injection of a saline control, and almost 30\% (5/17) of females released eggs following injection of LHRHa, but this difference was not significant (Fishers exact test $\mathrm{p}=0.116$ ). The mean body size (SVL) of females that released eggs (mean $\pm \mathrm{SE}=28.3 \pm 0.75)$ was not significantly different from females that did not release eggs (mean $\pm \mathrm{SE}=$ $27.58 \pm 0.48)(\mathrm{t}=-0.793, \mathrm{df}=15, \mathrm{p}=0.44)$. There was also no significant relationship between female body size $(\mathrm{SVL})$ and total clutch size $\left(\mathrm{r}^{2}=0.473, \mathrm{n}=5, \mathrm{p}=\right.$ 0.199 ). Of the females that responded positively to hormone treatment, all of them (5/5) released their clutches in discrete batches over 2-4 sampling times (Table 2). Females released between one and twelve eggs per batch, and average total clutch size was $15.2 \pm 2.67$ (Table 2). No female released eggs until $24 \mathrm{~h} \mathrm{PA}$, and only one female was still releasing eggs at $72 \mathrm{~h}$ PA (Figure 5). On average, females released the greatest proportion of their clutches between 24 and $48 \mathrm{~h} \mathrm{PA}$, with a peak in egg release at $36 \mathrm{~h}$ PA (Figure 5).

\section{In-vitro fertilisation}

On average, fertilisation success across females $(\mathrm{n}=5)$ was moderate (mean $\pm \mathrm{SE}=54.72 \pm 12.80 \%$ ), but there was considerable variation between females (Table 2). Of the eggs that were fertilised, all commenced embryonic development, but no embryos survived beyond gastrulation [44]. The exact stage of failure varied between 


\begin{tabular}{|c|c|c|c|c|}
\hline Treatment & $\begin{array}{l}\text { Time } \\
(\mathrm{PA})\end{array}$ & $\begin{array}{c}\text { Sperm } \\
\text { number }\end{array}$ & $\begin{array}{c}\text { Sperm } / \mathrm{mL}(\times \\
\left.10^{3}\right)\end{array}$ & $\begin{array}{c}\text { Sperm } \\
\text { viability }\end{array}$ \\
\hline $\mathrm{hCG}$ & 3 & $1.20 \pm 1.20$ & $0.086 \pm 0.086$ & $1.00 \pm 0.00$ \\
\hline hCG & 7 & $0.40 \pm 0.20$ & $0.009 \pm 0.005$ & $1.00 \pm 0.00$ \\
\hline hCG & 12 & $39.0 \pm 38.25$ & $1.72 \pm 1.703$ & $0.34 \pm 0.32$ \\
\hline hCG & 24 & $5.00 \pm 4.75$ & $0.16 \pm 0.147$ & $0.85 \pm 0.14$ \\
\hline hCG & 36 & $2.20 \pm 1.95$ & $0.27 \pm 0.263$ & $0.60 \pm 0.40$ \\
\hline hCG & 48 & $9.20 \pm 5.34$ & $0.03 \pm 0.022$ & $0.00 \pm 0.00$ \\
\hline hCG & 60 & $0.00 \pm 0.00$ & - & - \\
\hline hCG & 72 & $0.00 \pm 0.00$ & - & - \\
\hline LHRHa & 3 & $0.00 \pm 0.00$ & - & - \\
\hline LHRHa & 7 & $17.22 \pm 17.22$ & $1.111 \pm 1.111$ & $0.68 \pm 0.00$ \\
\hline LHRHa & 12 & $\begin{array}{c}101.55 \pm \\
67.28\end{array}$ & $3.113 \pm 1.837$ & $0.89 \pm 0.03$ \\
\hline LHRHa & 24 & $82.33 \pm 47.93$ & $3.507 \pm 1.937$ & $0.80 \pm 0.08$ \\
\hline LHRHa & 36 & $\begin{array}{l}233.88 \pm \\
99.73\end{array}$ & $10.106 \pm 4.018$ & $0.85 \pm 0.02$ \\
\hline LHRHa & 48 & $\begin{array}{c}149.00 \pm \\
67.42\end{array}$ & $0.776 \pm 0.368$ & $0.72 \pm 0.04$ \\
\hline LHRHa & 60 & $67.00 \pm 39.16$ & $0.313 \pm 0.162$ & $0.30 \pm 0.05$ \\
\hline LHRHa & 72 & $12.44 \pm 6.65$ & $0.733 \pm 0.389$ & $0.54 \pm 0.24$ \\
\hline
\end{tabular}

Values represent means \pm SEM

a female's egg batches, as well as between females (Table 2).

\section{Discussion}

Our study showed that hormone treatment induced gamete release in both male and female corroboree frogs, permitting us to test whether IVF can be used to augment captive breeding in this critically endangered species. Spermiation was induced following administration of either hCG or LHRHa, but these hormones were not equally effective. Both hormones led to approximately $80 \%$ of males releasing sperm, but there were significant differences in the speed and duration of response, and the number, concentration and proportion of live sperm released. Administration of hCG, led to a more rapid response, but LHRHa induced the release of a significantly higher number and concentration of viable sperm, and over a longer time period. This difference indicates that LHRHa was more effective at inducing spermiation in this species. That hCG and LHRHa elicited different responses was not unexpected because past research in anurans has shown that the relative efficacy of these hormones is highly species specific [5]. It is important to recognise, that as for the vast majority of anuran ART studies conducted to date, our study only tested each hormone at a single dose [5]. Therefore, to more thoroughly evaluate the relative efficacy of each hormone, it will be necessary to establish spermiation responses to $\mathrm{hCG}$ and LHRHa across a range of doses. Testing dose response relationships was beyond the scope of the current study, but this research will be incorporated into the recovery plan for the species.

Despite our finding that LHRHa was successful at inducing spermiation, hormone treated males did not release exceptionally high concentrations of sperm. On average, LHRHa treated males released approximately $4.5 \times 10^{3}$ sperm per millilitre, a value that is several orders of magnitude lower than hormonally induced sperm concentrations $\left(4.0 \times 10^{5}\right.$ to $4 \times 10^{7}$ sperm per millilitre) previously reported for anurans [22,24,39]. There may be several explanations why sperm concentrations were comparatively low in $P$. corroboree. First, the doses used may have been too low, or too high, to induce an optimal response. Even though we used concentrations approximating those found to be effective in a broad range of frog species [18,19], LHRHa may lack potency in $P$. corroboree. Another possibility is that males were not in prime physiological condition at the time of hormone treatment. In seasonally reproducing anurans such as $P$. corroboree, individuals typically coordinate their physiological state with environmental cues, which exert their effect by stimulating gonadotropin-releasing hormone neurons at the apex of the hypothalamus-pituitary-gonad axis [45]. In nature, spermatogenetic activity in $P$. corroboree commences several months prior to the onset of breeding [46], so if environmental changes that normally take place in spring (e. g. increasing photoperiod) were not suitably replicated in the captive environment, male investment in spermatogenic activity may have been limited prior to treatment. Another explanation for low sperm yield is that $P$. corroboree is not a species that invests heavily in spermatogenesis. Theoretically, anurans should only experience strong selection for high sperm production if male's either experience a high risk of sperm competition [47], are required to fertilise large egg clutches [48], or have exceptionally high mating rates [49], but all these conditions are absent in $P$. corroboree [50,51]. In fact, testes size relative to body size in $P$. corroboree is amongst the smallest reported in the family Myobatrachidae $[46,51]$, so assuming that testis size reflects sperm production capacity in anurans [27], male $P$. corroboree might actually be incapable of producing high sperm yields.

For females, administration of LHRHa stimulated the release of multiple batches of oocytes over a 24 hour period, indicating that hormone treatment was effective at inducing ovulation, and that final egg maturation was asynchronous [52]. However, the average percentage of females responding was low $(<30 \%)$, and the average clutch size (mean = approx 15 eggs) was at the lower 


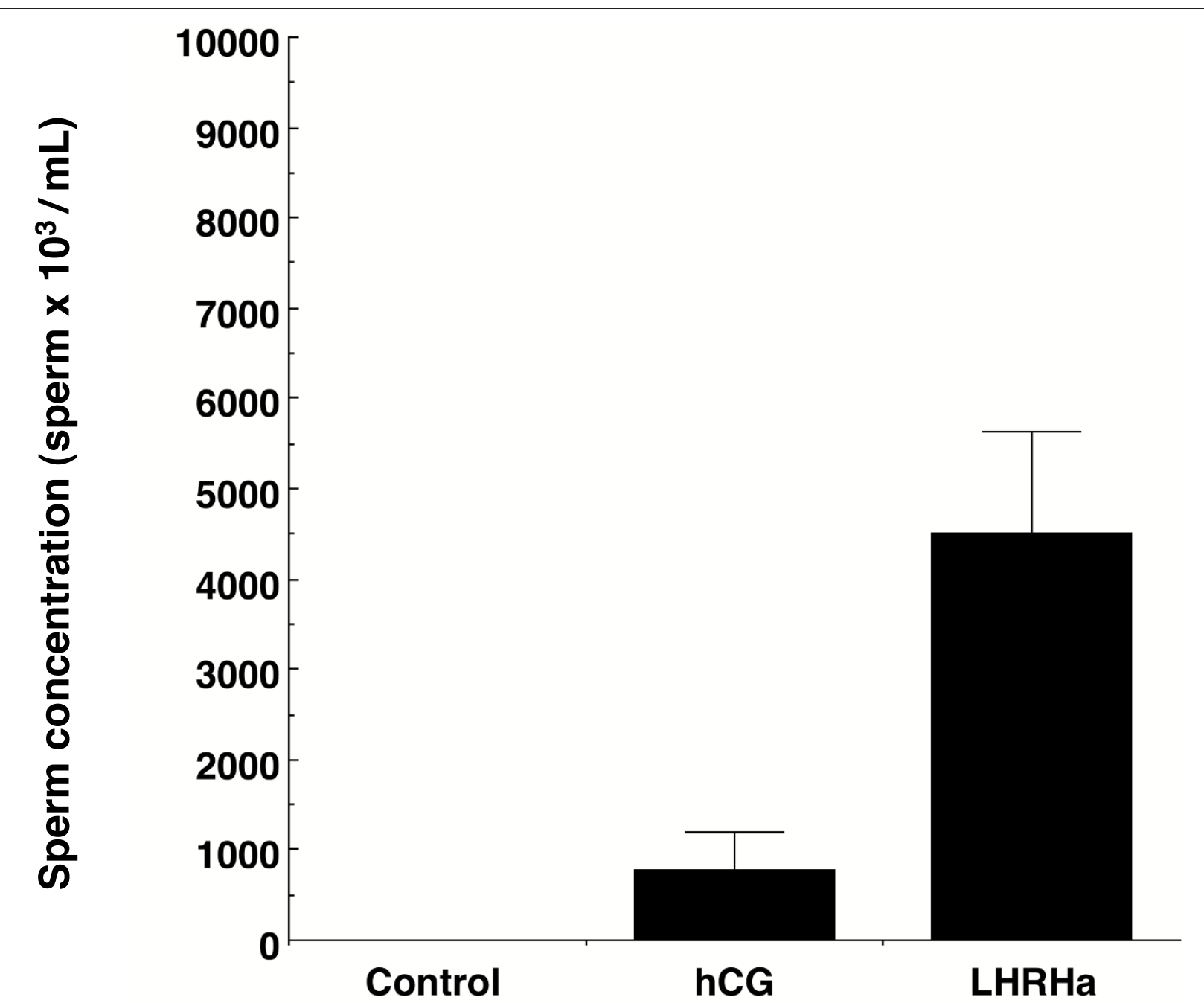

\section{Treatment}

Figure $\mathbf{3}$ Total concentration of sperm released by hormone treated males over a $\mathbf{7 2} \mathbf{h}$ sampling period. Values represent mean $\pm \mathrm{SEM}$ total concentration of spermatozoa released following subcutaneous injection of i) saline solution (control, $n=6$ males) ii) hCG ( $n=6$ males) or iii) LHRHa ( $n=11$ males).

end of the range (16-40 eggs) previously recorded for this species [50]. The suboptimal response might mean that LHRHa lacks potency in $P$. corroboree females, as was suggested for males (see above). Indeed, the ability of LHRHa to induce ovulation is known to vary considerably between anuran species. For example, doses required to reliably stimulate ovulation in the leptodactylid frog Eleutherodactylus coqui are 25 times higher than needed in the Wyoming toad Bufo baxteri $[8,17]$. Quantifying dose response relationships for female $P$. corroboree, as well as for males (see above), would provide valuable insight into the potency of LHRHa in this species. An alternative explanation is that phenotypic differences between test females influenced their responsiveness to hormone treatment. For example, in a recent study on boreal toads (Bufo boreas boreas), Roth et al. [23] showed that female age, body size and condition were all important factors influencing the efficacy of LHRHa treatment. However, in our study, females were of similar age (4-5 yrs) and there was no relationship between female body size and number of eggs released, so it is unlikely that these factors underpinned the variable responses reported. A more plausible explanation is that unresponsive females failed to ovulate because their oocytes were immature at the time of hormone treatment [42]. This explanation seems likely because post 


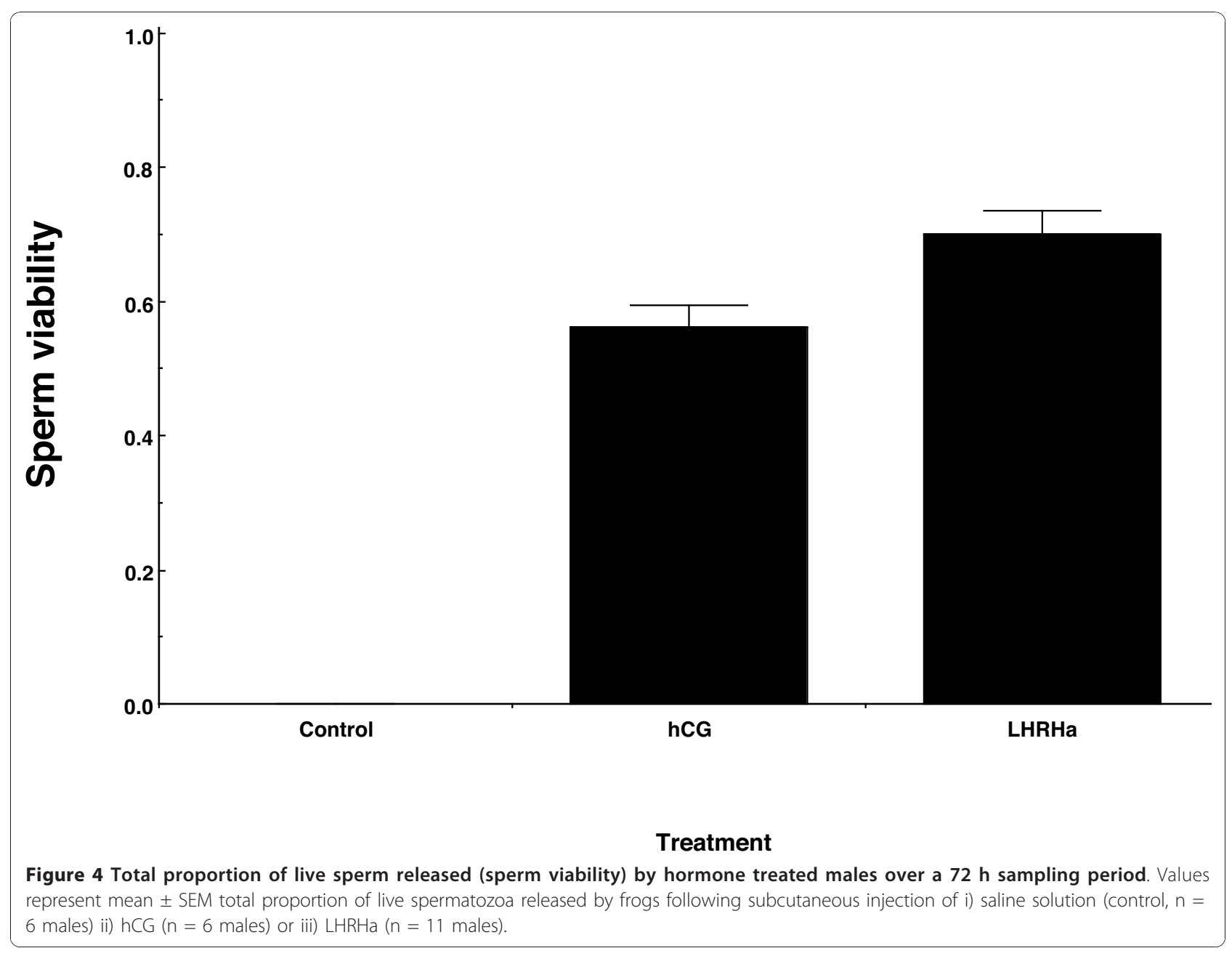

Table 2 Egg release patterns and IVF success for five Pseudophryne corroboree females

\begin{tabular}{|c|c|c|c|c|c|c|}
\hline Id & Time (PA) & Batch & Total eggs & $\%$ Fertilised & $\%$ Survival & Developmental stage at failure \\
\hline \multirow[t]{4}{*}{3060} & 24 & 1 & 12 & 75 & 0 & $4-6$ \\
\hline & 36 & 2 & 8 & 100 & 0 & $4-6$ \\
\hline & 48 & 3 & 1 & - & - & - \\
\hline & 60 & 4 & 1 & - & - & - \\
\hline \multirow[t]{4}{*}{7} & 24 & 1 & 2 & - & - & - \\
\hline & 36 & 2 & 5 & 40 & 0 & $9-10$ \\
\hline & 48 & 3 & 11 & 100 & 0 & $3-4$ \\
\hline & 60 & 4 & 2 & 100 & 0 & $3-4$ \\
\hline \multirow[t]{2}{*}{4080} & 36 & 1 & 4 & 25 & 0 & $4-6$ \\
\hline & 48 & 2 & 3 & 0 & 0 & $3-4$ \\
\hline \multirow[t]{2}{*}{809} & 24 & 1 & 12 & 41.7 & 0 & $9-10$ \\
\hline & 36 & 2 & 1 & 0 & 0 & - \\
\hline \multirow[t]{3}{*}{2090} & 36 & 1 & 8 & 100 & 0 & $3-4$ \\
\hline & 60 & 2 & 3 & 33.33 & 0 & $4-6$ \\
\hline & 72 & 3 & 3 & 100 & 0 & $3-4$ \\
\hline
\end{tabular}

NB: For females 7 and 3060, IVF was not performed at $24 \mathrm{~h}, 48 \mathrm{~h}$ and $60 \mathrm{~h}$ respectively (missing values), because eggs were not viable when released 


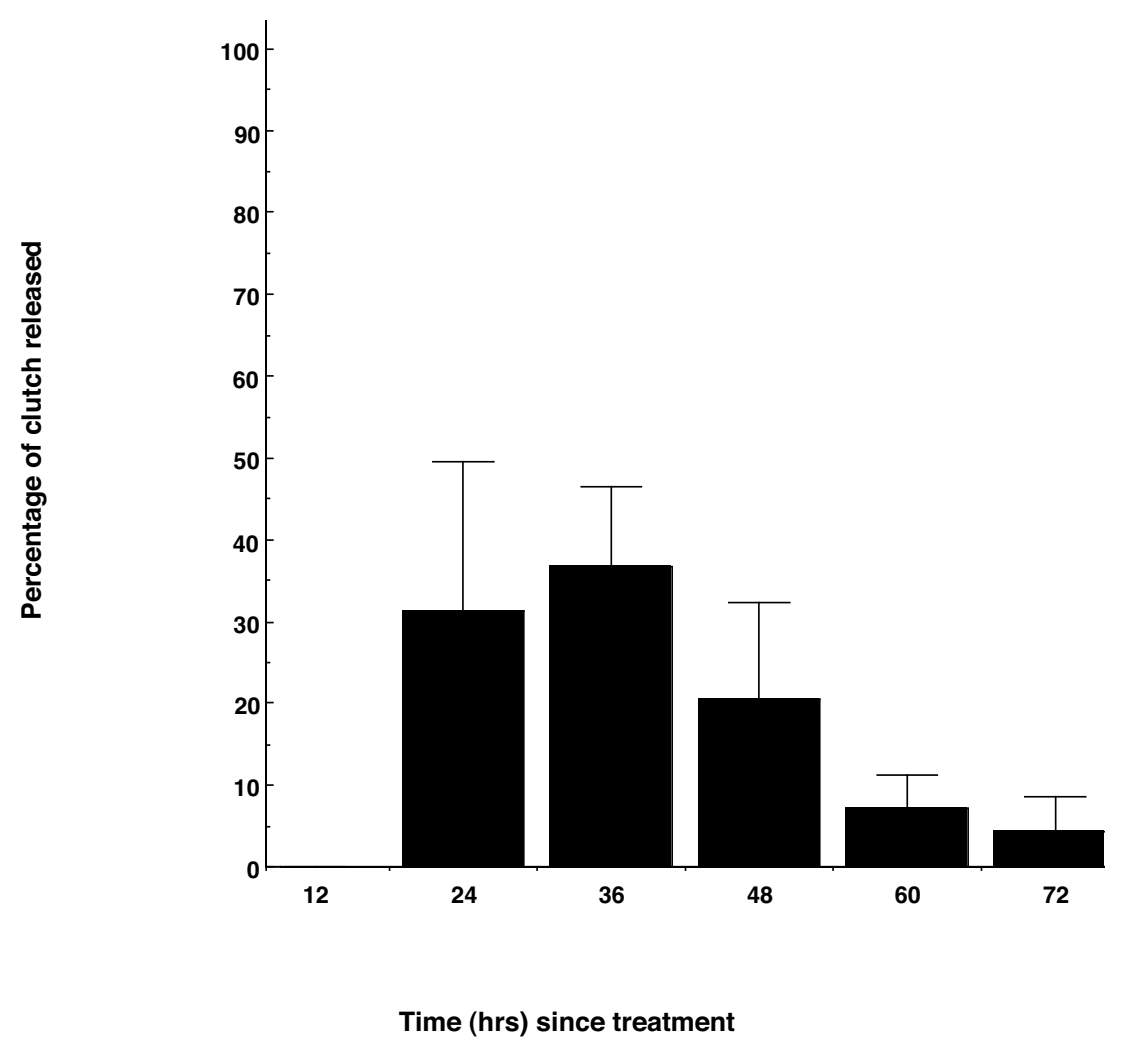

Figure 5 Percentage of total clutch released by female frogs $(n=5)$ every $12 \mathrm{~h}$ over a $72 \mathrm{~h}$ sampling period.

experimental tactile inspection of unresponsive females revealed that most individuals were still carrying small to medium sized oocytes.

In nature, female $P$. corroboree undergo rapid oocyte growth 4-8 weeks before the onset of breeding [46], so assuming that similar changes take place in captivity, our treatments may not have perfectly coincided with the time when females were undergoing the final stages of oogenesis. If females were treated too early, oocytes might not have been competent for ovulation [53], but if they were treated too late, oocytes may have already commenced reabsorption [46]. Increasing egg yield in $P$. corroboree may therefore require developing techniques for reliably assessing changes in oocyte growth and development [54]. Furthermore, it may be necessary to artificially accelerate and synchronise ova maturation prior to any attempt to induce ovulation. Past work with anurans has shown that this might be achieved by repeatedly administering females with low-dose injections of gonadotropins. For example, Browne et al. [8] reported that two priming injections of hCG, in combination with LHRHa, significantly increased the percentage of spawning females, the number of oocytes released, and the survival of fertilised eggs in the Wyoming toad Bufo baxteri.
Oocyte maturation in frogs might also be enhanced via in vitro or in vivo treatment with steroid stimulants $[53,55]$. The process of oocyte development in anurans has been extensively studied in Xenopus laevis and Rana pipiens and it is well established that the secretion of progesterone from late-stage follicles plays a fundamental role in germinal vesicle breakdown (GVBD) and oocyte maturation [55-63]. Furthermore, there is also experimental evidence to suggest that in vivo administration of progesterone can accelerate oocyte maturation and increase the effectiveness of hormone treatment. Specifically, Browne et al. [42] recently reported that administration of progesterone, in combination with LHRHa, significantly improved the number and quality of hormone-induced oocytes released by the toad Bufo fowleri. Based on these results, incorporating steroid treatment into future ART work with $P$. corroboree might be a valuable next step towards optimising ovulatory responses in this species.

Importantly, the hormone treatment protocols we employed permitted gametes to be collected and IVF to be attempted, indicating that there is real potential for ART to assist with the captive breeding of $P$. corroboree. However, the IVF trials resulted in variable levels of fertilisation success. Variable fertilisation success may have occurred because sperm concentrations were 
suboptimal. In previous anuran ART studies, concentrations of sperm resulting in high fertilisation success have been within the range of $5 \times 10^{5}$ to $1 \times 10^{6}$ sperm per $\mathrm{mL}$ [5], but we were restricted to using concentrations of less than $2.8 \times 10^{2}$ sperm per $\mathrm{mL}$, which may have greatly reduced the probability of gamete fusion. Alternatively, variable fertilisation success may have resulted because the osmolality of the fertilisation medium was inappropriate, as has been reported in the Australian myobatractid frog Limnodynastes tasmaniensis [27]. During the study all males were kept well hydrated, so if their spermic urine was too dilute, this may have significantly reduced the osmolality of the fertilisation medium. If so, sperm may have been activated soon after urine collection and lost viability before IVF was attempted. Furthermore, if osmolality was too low this could have resulted in the large egg capsules swelling too rapidly, making it impossible for individual sperm to penetrate an egg cortex. Clearly, further work will be needed to identify the primary cause of low fertilisation success. It may also be necessary to investigate alternative IVF techniques, such as intra-cytoplasmic sperm injection (ICSI). This more sophisticated IVF approach has been trialled in Bufo arenarum [64] and Xenopus laevis [65], and provides a promising solution for achieving high fertilisation success when numbers of spermatozoa are limiting [7].

Of greater immediate concern than suboptimal fertilisation, is the result that all embryos failed during early development. Early embryo failure may have occurred because hormonal induction impaired gamete viability [5]. In most studies testing the feasibility of IVF in anurans, sperm has been obtained from testes macerates, and embryo survival has been high [5,13,27-29]. However, in a recent study in which hormonally induced sperm was used to conduct IVF in the endangered toad Bufo baxteri, levels of embryo survival were also low [8]. These results suggest that there might be problems associated with using spermic urine to fertilize hormonally induced oocytes. Potential reasons for this are not obvious, so this is an area that may require research attention. An alternative explanation for embryo failure is that the incubation conditions employed were inappropriate for this species. Terrestrial breeding Pseudophryne species have extremely large and gelatinous eggs whose capsule size and surface area is primarily determined by hydration state [66]. Consequently, the amount of water present during incubation will significantly affect rates of gas exchange, and subsequently, embryo growth and survival [67]. If eggs were kept too hydrated, or were hydrated too early in development, this may have resulted in oxygen limitation within egg capsules, which in turn could have resulted in embryo mortality [67]. However, this seems unlikely because our incubation conditions were similar to those previously used to successfully rear Pseudophryne guentheri embryos (Silla unpublished data). As such, we suspect that there may be a more intrinsic explanation for embryo failure.

In a recent study that used a cross classified breeding design to examine genetic compatibility in Pseudophryne bibronii, a sister species to $P$. corroboree, we discovered that crosses made between individuals from the same population had high embryo survival, but those made between populations experienced complete early embryo failure (Byrne and Silla, unpublished data). These results indicate that terrestrial toadlets may be susceptible to high levels of genetic incompatibility, as has been reported in other Australian anurans [68,69]. Critically, the frogs used in our study were all sourced from mixed populations, so there is a real possibility that embryo failure was indeed linked to developmental problems arising from genetic incompatibility. To address this potential problem, it will be necessary to conduct future IVF trials in $P$. corroboree using individuals derived from the same source populations.

\section{Conclusion}

In conclusion, this study demonstrated that exogenous hormones induced spermiation and ovulation in the southern corroboree frog $P$. corroboree. The hormonetreatment protocols used did not lead to exceptionally large numbers of gametes being released, but did permit the conduction of IVF, which resulted in moderate fertilisation success. Critically, however, all embryos failed during early stages of development. Embryo developmental failure may have occurred either because hormone treatment compromised gamete viability or because the incubation conditions employed were inappropriate. Alternatively, failure may have been linked to genetic incompatibility resulting from crosses being made between frogs sourced from several different populations. Additional work will be required to increase gamete yield for IVF and identify the causation of embryo failure. The findings are an important first step towards developing artificial reproductive technologies for assisting with the captive breeding of Australia's most critically endangered anuran.

\section{Acknowledgements}

Thanks to Dale Roberts, Dave Hunter and four anonymous referees for comments on the manuscript. The work was supported by grants from the NSW Department of Environment, Climate Change and Water (DECCW), the Corroboree Frog Conservation Trust, the Murray Catchment Management Authority (Murray CMA) and the Foundation for National Parks and Wildlife (FNPW). The research was also supported by Abbott Australia. The project was part of a multi-pronged recovery program for the Southern Corroboree Frog. The recovery team includes experts from the NSW Department of Environment, Climate Change and Water (Dr David Hunter), the Amphibian Research Cente (Dr Gerry Marintelli and Erika Marintelli), Taronga Zoo (Dr Peter Harlow and Michael McFadden), Tidbinbilla Nature Reserve (Murray 
Evans), Healesville Sanctuary (Kristy Penrose), Melbourne Zoo (Raelene Hobbs), and the Murray Catchment Management Authority (Elisa Tack).

\section{Author details}

${ }^{1}$ School of Biological Sciences, Monash University, Melbourne Vic, Australia.

${ }^{2}$ School of Animal Biology, University of Western Australia, Perth, Australia.

\section{Authors' contributions}

PGB and AJS were equally responsible for designing the experiments, coordinating and conducting the experiments, analysing the data and writing the manuscript. Both authors read and approved the final manuscript.

\section{Competing interests}

The authors declare that they have no competing interests.

Received: 27 August 2010 Accepted: 29 November 2010 Published: 29 November 2010

\section{References}

1. Willis KJ, Bhagwat SA: Biodiversity and climate change. Science 2009, 326:806-807

2. Stuart SN, Chanson JS, Cox NA, Young BE, Rodrigues ASL, Fischman DL, Waller RW: Status and Trends of Amphibian Declines and Extinctions Worldwide. Science 2004, 306:1783-1786.

3. Wells KD: The Ecology and Behavior of Amphibians Chicago: The University of Chicago Press; 2007

4. Gascon C, Collins JP, Moore RD, Church DR, McKay JE, Mendelson JR: Amphibian conservation action plan. IUCN/SSC Amphibian Specialist Group 2007, 64.

5. Kouba AJ, Vance CK, Willis EL: Artificial fertilization for amphibian conservation: current knowledge and future considerations. Theriogenology 2009, 71:214-227.

6. Mann RM, RV H, CB C: Hormonal induction of spermiation, courting behavior and spawning in the southern bell frog, Litoria raniformis. Zoo Biol 2010, 29:1-9.

7. Clulow J, Mahoney M, Browne R, Pomering M, Clark A: Application of assisted reproductive technologies (ART) to endangered anuran amphibians. In Declines and disappearances of Australian frogs. Edited by: Campbell A. Canberra, ACT: Environment Australia; 1999:219-225.

8. Browne RK, Seratt J, Vance C, Kouba A: Hormonal priming, induction of ovulation and in-vitro fertilization of the endangered Wyoming toad (Bufo baxteri). Reprod Biol Endocrinol 2006, 4:34.

9. Rugh R: Experimental Embryology. 3 edition. Minneapolis, USA: Burgess; 1962.

10. Easley KA, Culley DD, Horseman ND, Penkala JE: Environmental influences on hormonally induced spermiation of the bullfrog Rana catesbiana. J Exp Zool 1979, 207:407-416.

11. Creaser CW, Gorbman A: Species specificity of the gonadotropic factors in vertebrates. Q Rev Biol 1939, 14:311-331.

12. Galli-Mainini C: Pregnancy test using the male toad. J Clin Endocrinol Metab 1947, 7:653-658

13. Cabada MO: Sperm concentration and fertilization rate in Bufo arenarum (Amphibian: Anura). J Exp Biol 1975, 62:481-486.

14. Redshaw MR: The hormonal control of the amphibian ovary. Am Zool 1972, 12:289-306.

15. Creaser CW, Gorbman A: Species specificity of the gonadotrophic factors in vertebrates. Q Rev Biol 1939, 14:311-331.

16. Licht $P$ : Induction of spermiation in anurans by mammalian pituitary gonadotropins and their subunits. Gen Comp Endocrinol 1973, 20:522-529.

17. Michael SF, Buckley C, Toro E, Estrada AR, Vincent S: Induced ovulation and egg deposition in the direct developing anuran Eleutherodactylus coqui. Reprod Biol Endocrinol 2004, 2:6.

18. Goncharov BF, Shubravy OI, Serbinova IA, Uteshev VK: The USSR programme for breeding amphibians, including rare and endangered species. Int Zoo Yearbk 1989, 28:10-21.

19. Kouba AJ, Vance CK: Applied reproductive technologies and genetic resource banking for amphibian conservation. Reprod Fertil Dev 2009, 21:719-737.
20. Norris DO: III. Tropic hormones of the adenohypophysis. In Vertebrate Endocrinology.. 4 edition. Edited by: Norris DO. San Diego: Academic Press; 2007:125-140.

21. Whitaker BR: Reproduction. In Amphibian Medicine and Captive Husbandry. Edited by: Wright KM, Whitaker BR. Malabar FL: Krieger Publishing Company; 2001:285-307.

22. Waggener WL, Carrol EJ: A method for hormonal induction of sperm release in anurans (eight species) and in vitro fertilization in Lepidobatrachus species. Dev Growth Differ 1998, 40:19-25.

23. Roth TL, zymanski DC, Keyster ED: Effects of age, weight, hormones, and hibernation on breeding success in boreal toads (Bufo boreas boreas). Theriogenology 2010, 73:501-511.

24. Obringer AR, O'Brian JK, Saunders RL, Yamamoto K, Kikuyama S, Roth TL: Characterization of the spermiation response, luteinizing hormone release and sperm quality in the American toad (Bufo americanus) and the endangered Wyoming toad (Bufo baxteri). Reprod Fertil Dev 2000, 12:51-58.

25. Trudeau VL, Somoza GM, Natale GS, Pauli B, Wignall J, JAckman P, Doe K, Schueler FW: Hormonal induction of spawning in 4 species of frogs by coinjection with a gonadotropin-releasing hormone agonist and a dopamine antagonist. Reprod Biol Endocrinol 2010, 8:36-44.

26. Schultz TW, Dawson DA: Housing and husbandry of Xenopus for oocyte production. Lab Animal 2003, 32:34-39.

27. Edwards D, Mahony MJ, Clulow J: Effect of sperm concentration, medium osmolality and oocyte storage on artificial fertilisation success in a myobatrachid frog (Limnodynastes tasmaniensis). Reprod Fertil Dev 2004, 16:347-354.

28. Hollinger TG, Corton GL: Artificial fertilisation of gametes from the South African clawed frog Xenopus laevis. Gamete Res 1980, 3:45-57.

29. Browne RK, Clulow J, Mahony M, Clark A: Successful recovery of motility and fertility of cryopreserved cane toad (Bufo marinus) sperm. Cryobiology 1998, 37:339-345

30. Hero M, Morrison C, Gillespie G, Roberts JD, Newell D, Meyer E, McDonald K, Lemckert F, Mahony M, Osborne W, et al: Overview of the conservation status of Australian Frogs. Pac Conserv Biol 2006, 12:313-320.

31. Gillespie G, Traher R, Banks C: ARAZPA Amphibian Action Plan. Report to the Australasian Regional Association of Zoological Parks and Aquaria; 2007.

32. Osborne WS: The biology and management of the Corroboree Frog (Pseudophryne corroboree) in NSW. Species Management Report NPWS 1991.

33. DECCW: DRAFT National recovery plan for the Southern Corroboree frog Pseudophryne corroboree and the Northern Corroboree frog Pseudophryne pengilleyi. NSW Department of Environment, Climate Change and Water; 2010.

34. Osborne W, Hunter D, Hollis G: Population declines and range contraction in Australian alpine frogs. In Declines and Disappearances of Australian Frogs. Edited by: Campbell A. Canberra: Environment Australia; 1999:145-157.

35. Hunter D, Pietsch R, Marantelli G, McFadden M, Harlow P: Field research, recovery actions, and recommendations for the southern corroboree frog (Pseudophryne corroboree) recovery program: 2007 - 2009. Murray Catchment Management Authority 2009.

36. Hunter D: The conservation and demography of the southern corroboree frog (Pseudophryne corroboree). M. Sc University of Canberra, Applied Ecology Research Group; 2000.

37. Quinn AE: Development of a DNS sex marker for the endangered Southern Corroboree frog (Pseudophryne corroboree). NSW Department of Conservation, Climate Change and Water 2009, 1-21.

38. Garner DL, Johnson LA: Viability assessment of mammalian sperm using SYBR-14 and propidium iodide. Biol Reprod 1995, 53:276-284.

39. Sherman $\mathrm{CDH}$, Uller T, Wapstra $\mathrm{E}$, Olsson M: Within-population variation in ejacualte characteristics in a prolonged breeder, Peron's treefrog, Litoria peronii. Naturwissenschaften 2008, 95:1055-1061.

40. Silla AJ: Effects of luteinizing hormone-releasing hormone and argininevasotocin on the sperm-release response of Gunther's Toadlet, Pseudophryne guentheri. Reprod Biol Endocrinol 2010, 8:139.

41. García-González F, Simmons LW: Sperm viability matters in insect sperm competition. Curr Biol 2005, 15:271-275.

42. Browne RK, Seratt J, Vance C, Kouba A: Progesterone improves the number and quality of hormonally induced fowler toad (Bufo fowleri) oocytes. Reprod Biol Endocrinol 2006, 4:3. 
43. Rugh R: Experimental Embryology Minneapolis: Burgess Publishing Co; 1948

44. Gosner KL: A simple table for staging anuran embryos and larvae with notes on identification. Herpetologica 1960, 16:183-190.

45. Burmeister SS, Wilczynski W: Social signals regulate gonadotropinreleasing hormone neurons in the green treefrog. Brain Behav Evol 2005, 65:26-32.

46. Pengilley RK: Natural history of Pseudophryne spp. (Anura: Myobatrachidae) in the Southern Highlands of N.S.W., Australia. Sydney Basin Naturalist 1992, 1:9-29.

47. Parker GA, Ball M, Stockley P, Gage MJG: Sperm competition games: individual assessment of sperm competition intensity by group spawners. Proc R Soc Lond B Biol Sci 1996, 263:1291-1297.

48. Emerson SB: Testis size variation in frogs: testing the alternatives. Behav Ecol Sociobiol 1997, 41:227-235.

49. Parker GA, Ball MA: Sperm competition, mating rate and the evolution of testis and ejaculate sizes: a population model. Biol Lett 2005, 1:235-238.

50. Pengilley RK: Breeding biology of some species of Pseudophryne (Anura: Leptodactylidae) of the Southern Highlands, New South Wales. Aust Zool 1973, 18:15-30.

51. Byrne PG, Roberts JD, Simmons LW: Sperm competition selects for increased testes mass in Australian frogs. J Evol Biol 2002, 15:347-355.

52. Mansour N, Lahnsteiner F, Patzner RA: Collection of gametes from live axolotyl, Ambystoma mexicanum, and standardization of in vitro fertilization. Theriogenology 2010.

53. Hammes SR: Steroids and Oocyte Maturation-A New Look at an Old Story. Mol Endocrinol 2004, 18:769-775.

54. Reyer HU, Bättig I: Identification of reproductive status in female frogs-A quantitative comparison of nine methods. Herpetologica 2004, 60:349-357.

55. Masui Y, Clarke HJ: Oocyte maturation. Int Rev Cytol 1979, 57:185-282.

56. Schuetz AW: In vitro induction of ovulation and oocyte maturation in Rana pipiens ovarian follicles: effects of steroidal and non-steroidal hormones. J Exp Zool 1971, 178:377-385.

57. LaMarca MJ, Westphal LM, Rein DA: Gonadotropins and the timing of progesterone-induced meiotic maturation of Xenopus laevis oocytes. Dev Biol 1985, 109:32-40.

58. Marot J, Belle R, Ozon R: In vitro facilitation of Xenopus oocyte maturation by subthreshold doses of progesterone. Dev Biol 1977, 59:91-95.

59. DeAlbuja CM, Campos M, Pino EMD: Role of progesterone on oocyte maturation in the egg-brooding hylid frog Gastrotheca riobambae (Fowler). J Exp Zool 1983, 227:271-276.

60. Schuetz AW: Role of hormones in oocyte maturation. Biol Reprod 1974 10:150-178.

61. Masui Y: Relative roles of the pituitary, follicle cells, and progesterone in the induction of oocyte maturation in Rana pipiens. J Exp Zool 1967, 166:365-376.

62. Fortune JE: Steroid production by Xenopus ovarian follicles at different developmental stages. Dev Biol 1983, 99:502-509.

63. Medina MF, Ramos L, Crespo CA, Gonzalez-Calver S, Fernandez SN: Changes in serum sex steroid levels throughout the reproductive cycle of Bufo arenarum females. Gen Comp Endocrinol 2004, 136:143-151.

64. Zelarayan LI, Oterino J, Buhler MI: Spontaneous maturation in Bufo arenarum oocytes: follicle wall involvement, respiratory activity and seasona influences. J Exp Zool 1995, 272:356-362.

65. Brun R: Studies on fertilisation in Xenopus laevis. Biol Reprod 1974, 11:513-518.

66. Mitchell NJ, Seymour RS: Effects of temperature on energy cost and timing of embryonic and larval development of the terrestrially breeding moss frog, Bryobatrachus nimbus. Physiol Biochem Zool 2000, 73:829-840

67. Bradford DF, Seymour RS: Influence of water potential on growth and survival of the embryo and gas conductance of the egg, in a terrestrial breeding frog, Pseudophryne bibronii. Physiol Zool 1988, 61:470-474.

68. Dziminski MA, Roberts JD, Simmons LW: Fitness consequences of parental compatibility in the frog Crinia georgiana. Evolution 2008, 62:879-886.

69. Sherman CDH, Wapstra E, Uller T, Olsson M: Males with high genetic similarity to females sire more offspring in sperm competition in Peron's tree frog Litoria peronii. Proc R Soc Lond B Biol Sci 2008, 275:971-978. doi:10.1186/1477-7827-8-144

Cite this article as: Byrne and Silla: Hormonal induction of gamete release, and in-vitro fertilisation, in the critically endangered Southern Corroboree Frog, Pseudophryne corroboree. Reproductive Biology and Endocrinology 2010 8:144.

\section{Submit your next manuscript to BioMed Central and take full advantage of:}

- Convenient online submission

- Thorough peer review

- No space constraints or color figure charges

- Immediate publication on acceptance

- Inclusion in PubMed, CAS, Scopus and Google Scholar

- Research which is freely available for redistribution 